\title{
Synthesis and TDDFT Investigation of New Maleimide Derivatives Bearing Pyrrole and Indole Ring
}

\author{
Yasuhiro Shigemitsu, ${ }^{1}$ Kaori Komiya, ${ }^{2}$ Naoko Mizuyama, ${ }^{3}$ Masayori Hagimori, ${ }^{4}$ \\ and Yoshinori Tominaga ${ }^{2}$ \\ ${ }^{1}$ Industrial Technology Center of Nagasaki, 2-1303-8, Ikeda, Omura, Nagasaki 856-0026, Japan \\ ${ }^{2}$ Faculty of Environmental Studies, Nagasaki University, 1-14, Bunkyo-machi, Nagasaki 852-8131, Japan \\ ${ }^{3}$ Department of Pharmacy, Saga University Hospital, 5-1-1, Nabeshima, Saga 849-8521, Japan \\ ${ }^{4}$ Faculty of Pharmaceutical Sciences, Nagasaki International University, 2825-7, Huis Ten Bosch, Sasebo 859-3298, Japan \\ Correspondence should be addressed to Yasuhiro Shigemitsu, shige@tc.nagasaki.go.jp
}

Received 29 October 2008; Accepted 15 January 2009

Recommended by Cyril Parkanyi

\begin{abstract}
A novel series of heterocycles were obtained through the condensation reaction of 4-methylthiomaleimides with pyrroles and indoles. The newly synthesized compounds exhibit their major electronic absorption peaks ranging $435-504 \mathrm{~nm}$ in solution at room temperature. Time-dependent density-functional theory (TDDFT) calculations were systematically performed in order to elucidate their structure-color relationships, using a set of exchange-correlation (XC) functionals. The TDDFT computational scheme employing PCM-TDDFT/6-31+G(d,p)//DFT/6-311G(d,p) level of theory gave qualitatively satisfactory results in their $\lambda_{\max }$ predictions.
\end{abstract}

Copyright (C) 2009 Yasuhiro Shigemitsu et al. This is an open access article distributed under the Creative Commons Attribution License, which permits unrestricted use, distribution, and reproduction in any medium, provided the original work is properly cited.

\section{Introduction}

Maleimides are widely known as active electrophilic reagents to readily react with a variety of dienes and 1,3-dipoles including azomethine ylide, carbonyl ylide and, nitorenes, leading to various heterocycles [1]. We have explored the abundant synthetic potential of the new functionalized maleimides which can effectively be converted to fused pyridazine derivatives [2] and polymethine dyes [3, 4]. Herein we report the new series of dyes bearing push (pyrrole, indole)pull (maleimide) systems. The computational investigations are also described for their first intense electric absorption peaks using TD-DFT [5], which is widely used in electronic transition energy predictions for many molecules $[6,7]$.

\section{Synthesis and Electronic Spectra}

A series of 4-methylthiomaleimides $\mathbf{1 a}-\mathbf{1 c}$ were found to undergo addition-elimination reactions with pyrrole $\mathbf{2 a - 2} \mathbf{b}$ and indoles $\mathbf{4 a - 4 c}$ to give new compounds $\mathbf{3 a}-\mathbf{3 d}$ and $\mathbf{5 a}-$ $5 \mathrm{~g}$ which are listed in Table 1 and the synthetic scheme is illustrated in Figure 1.
In details, compounds $\mathbf{1 a}$ and $\mathbf{1 b}$ reacted with pyrrole 2a under refluxing in acetic acid to afford methyl 1-methyl4-(pyrrol-2-yl)-2,5-dioxo- $1 H$-pyrrole-3-carbonitrile $\mathbf{3 a}$ and methyl 1-methyl-4-(pyrrol-2-yl)-2,5-dioxo- $1 H$-pyrrole-3carboxylate $3 \mathbf{b}$, respectively, where the electrophilic attack of $\mathbf{1 a}$ and $\mathbf{1 b}$ to $\mathbf{2 a}$ selectively took place on 2-position of pyrrole ring. When using $N$-methylpyrrole $\mathbf{2 b}$ instead of $2 \mathbf{a}$, the attack on the 2-position competes with that on 3 -position of $\mathbf{2 b}$. In the same way, methyl 1-methyl-4(methylpyrrol-2-yl)-2,5-dioxo-1H-pyrrole-3-carboxylate 3d was obtained as mixture with the corresponding 1-methyl4-(methylpyrrol-3-yl)-2,5-dioxo-1H-pyrrole-3-carboxylate. The reaction of indoles $\mathbf{4 a - c}$ smoothly proceeded in a manner similar as in the case of pyrroles. The electrophilic attack selectively took place at 3-position of indole ring. 1a reacted with $\mathbf{4 a - c}$ to give the corresponding compound $\mathbf{5 a}-\mathbf{c}$. The reaction yield was lowered in order of $\mathbf{5 a}>\mathbf{5 b}$ $>5 \mathrm{c}$, reflecting relative magnitude of steric hindrance at the 2-position. Reaction between $\mathbf{1 c}$ and $\mathbf{4 a}$ afforded the corresponding adduct $\mathbf{5 d}$, but the yield was significantly lowered than $\mathbf{5 a}-\mathbf{c}$. $\mathbf{1} \mathbf{b}$ reacted with $4 \mathbf{a}-\mathbf{c}$ to give the 
TABLE 1: Recaptulatives of the newly synthesized compounds along with the key geometrical parameters $(r, \theta)$.

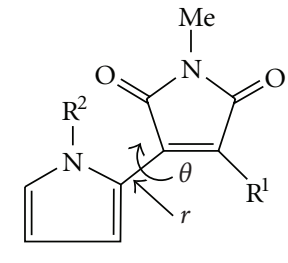

$3 a-3 d$

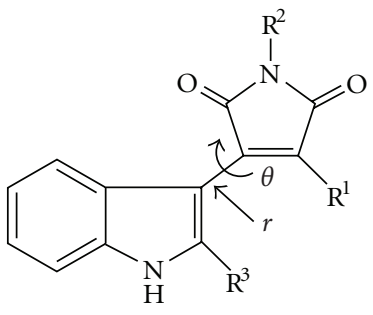

$5 \mathrm{a}-5 \mathrm{~g}$

\begin{tabular}{|c|c|c|c|}
\hline Entry & $\mathrm{R}^{1}$ & $\mathrm{R}^{2}$ & $\mathrm{R}^{3}$ \\
\hline $3 a$ & $\mathrm{CN}$ & $\mathrm{H}$ & 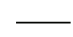 \\
\hline $3 b$ & COOMe & $\mathrm{H}$ & 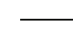 \\
\hline $3 c$ & $\mathrm{CN}$ & $\mathrm{Me}$ & 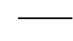 \\
\hline $3 d$ & COOMe & $\mathrm{Me}$ & $\longrightarrow$ \\
\hline $5 a$ & $\mathrm{CN}$ & $\mathrm{Me}$ & $\mathrm{H}$ \\
\hline $5 b$ & $\mathrm{CN}$ & $\mathrm{Me}$ & $\mathrm{Me}$ \\
\hline $5 c$ & $\mathrm{CN}$ & $\mathrm{Me}$ & $\mathrm{C}_{6} \mathrm{H}_{5}$ \\
\hline $5 d$ & COOMe & $\mathrm{H}$ & $\mathrm{H}$ \\
\hline $5 e$ & COOMe & $\mathrm{Me}$ & $\mathrm{H}$ \\
\hline $5 f$ & COOMe & $\mathrm{Me}$ & $\mathrm{Me}$ \\
\hline $5 g$ & COOMe & $\mathrm{Me}$ & $\mathrm{C}_{6} \mathrm{H}_{5}$ \\
\hline
\end{tabular}

corresponding $\mathbf{5 e}-\mathbf{g}$ in good yield. Details of the synthetic scheme are described in Supplementary Materials available online at doi:10.1155/2009/413219.

The UV/vis spectra were consistently measured in ethanol at room temperature. The first intense peaks of $5 \mathbf{a}-\mathbf{g}$ appeared around $444-504 \mathrm{~nm}$, bathochromically shifted from those of $\mathbf{3 a} \mathbf{a}-\mathbf{d}$, owing to their more extended $\pi$-conjugation. The hyperconjugative effects of $N$-methyl group on maleimide ring invoked $26 \mathrm{~nm}$ bathochromic shift observed between $\mathbf{5 a}$ and $\mathbf{5 d}$. The methyl and phenyl group at 2-position of indole ring induce 27 and $34 \mathrm{~nm}$ bathochromic shift, respectively, among $\mathbf{5 a}, \mathbf{5 b}$, and $\mathbf{5 c}$. The substitution of COOMe to $\mathrm{CN}$ at 3-position on maleimide ring resulted in $14 \mathrm{~nm}$ shift, as observed between $\mathbf{5 a}$ and $\mathbf{5 e}$.

\section{Computational Details}

The computations were carried out using GAUSSIAN03 program [8]. The Graphical representations of orbitals and of subtraction electron density were created by ChemCraft Software [9].

The ground-state geometry optimizations were carried out based on DFT using B3LYP hybrid functional combined with a series of Pople's standard basis sets (6-31G, 6-31G $(d, p), 6-311 G(d, p), 6-311 G(2 d, 2 p)$, 6$31+G(d, p), 6-311++G(d, p)$, and $6-311++G(2 d, 2 p))$. The optimized geometries were validated with the results that<smiles>[X]C1=C(C)C(=O)N(C(C)(C)C)C1=O</smiles><smiles>Cn1cccc1C(=O)O</smiles>

(1a: $\mathrm{R}^{1}=\mathrm{CN}$ 1b: $\mathrm{R}^{1}=\mathrm{COOMe}$ ) (2a: $\mathrm{R}^{2}=\mathrm{H}$, 2b: $\mathrm{R}^{2}=\mathrm{Me}$ )

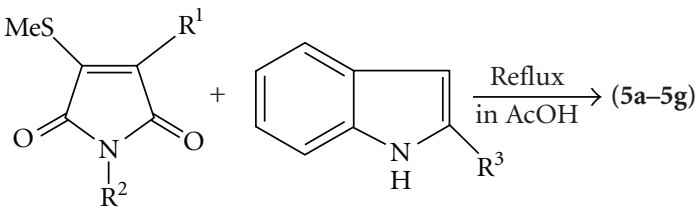

$$
\begin{array}{rlrl}
\left(\text { la: } \mathrm{R}^{1}\right. & =\mathrm{CN}, \mathrm{R}^{2}=\mathrm{Me} & \left(\mathbf{4 a}: \mathrm{R}^{3}=\mathrm{H}\right. \\
\text { 1b: } \mathrm{R}^{1}=\text { COOMe, } \mathrm{R}^{2}=\mathrm{Me} & & \text { 4b: } \mathrm{R}^{3}=\mathrm{Me} \\
\text { 1c: } \left.\mathrm{R}^{1}=\text { COOMe, } \mathrm{R}^{2}=\mathrm{H}\right) & \text { 4c: } \left.\mathrm{R}^{3}=\mathrm{C}_{6} \mathrm{H}_{5}\right)
\end{array}
$$

Figure 1: Synthesis diagram of $\mathbf{3 a - 3 d}$ and $\mathbf{5 a}-\mathbf{5 g}$.

no negative vibration frequencies were found for all the molecules.

In TDDFT calculations on the DFT-optimized geometry,a series of XC-functionals was employed; generalized gradient approximation (BLYP, PBE0, VSXC), hybrid type (B3PW91, B3LYP, O3LYP, MPW1PW91) and Handy's asymptotically corrected functional HCTH/407 to obtain the vertical excitation energies and their associated oscillator strengths.

In both steps of geometry optimization and TDDFT calculations, solvent effects of ethanol were included using the nonequilibrium polarizable continuum model (PCM) [10].

\section{Results and Discussion}

4.1. A Model Compound 3a. As a prototypical study, 3a was examined in details to assess how the set of computational parameters affect on TDDFT excitation energies.

Two-key geometrical parameters, the single bond connecting two moieties $(r)$ and the interring torsion angle $(\theta)$, are defined in Table 1 . The two parameters are consistently referred to hereafter for the remaining compounds $\mathbf{3 b} \mathbf{b} \mathbf{d}$ and $\mathbf{5 a}-\mathbf{g}$. The bond length $(r=1.405 \AA)$, considerably shorter than the standard single $\mathrm{C}-\mathrm{C}$ bond length by c.a. $0.1 \AA$, indicates moderate electronic resonance between the two moieties. Table 2 shows the evolution of $\lambda_{\max }$ as a function of basis sets used in both geometry optimizations and TDDFT calculations. As for the basis set effect on the geometry optimizations, we notice the uniform role of polarization, valence-splitting, and diffuse functions. For instance, the most extensive TDDFT using $6-311++\mathrm{G}(2 \mathrm{~d}, 2 \mathrm{p})$ gave $\lambda_{\max }$ blue shift by $16 \mathrm{~nm}$ from 6-31G- to 6-31G(d,p)-optimized geometry. The valencetriple-zeta basis set $6-311 \mathrm{G}(\mathrm{d}, \mathrm{p})$ instead of valence-double basis $6-31 G(d, p)$ yielded $5 \mathrm{~nm}$ blue shift. $6-31+G(d, p)$ basis set, augmented by single-diffuse function, shifted 
TABLE 2: $\lambda_{\max }$ (in $\mathrm{nm}$ ) dependence of $\mathbf{3 a}$ on the basis sets used for geometry optimization (DFT) and TD-DFT.

\begin{tabular}{|c|c|c|c|c|c|c|c|}
\hline & \multicolumn{7}{|c|}{ Geometry basis set (DFT) } \\
\hline & $6-31 G$ & $\begin{array}{c}6-31 \\
G(d, p)\end{array}$ & $\begin{array}{l}6-311 \\
G(d, p)\end{array}$ & $\begin{array}{c}6-311 \\
G(2 d, 2 p)\end{array}$ & $\begin{array}{l}6-31+ \\
G(d, p) \\
\end{array}$ & $\begin{array}{c}6-311++ \\
\mathrm{G}(\mathrm{d}, \mathrm{p})\end{array}$ & $\begin{array}{l}6-311++ \\
G(2 d, 2 p)\end{array}$ \\
\hline \multicolumn{8}{|l|}{ TD-DFT Basis set } \\
\hline $6-31 G$ & 460 & 445 & 440 & 438 & 445 & 440 & 439 \\
\hline $6-311 G(2 d, 2 p)$ & 461 & 446 & 440 & 439 & 446 & 441 & 439 \\
\hline $6-31+G(d)$ & 471 & 456 & 450 & 448 & 456 & 451 & 449 \\
\hline $6-31+G(d, p)$ & 472 & 456 & 451 & 449 & 457 & 451 & 450 \\
\hline $6-311++G(2 d, 2 p)$ & 473 & 457 & 452 & 450 & 458 & 452 & 451 \\
\hline
\end{tabular}

All DFT and TD-DFT calculations using B3LYP functional.

All DFT and TD-DFT calculations using PCM option with a built-in dielectronic constant of ethanol (24.55).

TABLE 3: Low-lying valence singlet excited states of 3a.

\begin{tabular}{|c|c|c|c|c|c|}
\hline \multirow{2}{*}{ state } & \multicolumn{3}{|c|}{ This work $^{(a)}$} & \multicolumn{2}{|c|}{ Expl. } \\
\hline & main config. & $\lambda_{\max }(\mathrm{nm})$ & oscillator strength & $\lambda_{\max }(\mathrm{nm})$ & $\log \varepsilon$ \\
\hline (1) CT: $\pi-\pi^{*}$ & H->L: 0.61 & 449 & 0.34 & 459 & 4.30 \\
\hline (2) LE: $\pi-\pi^{*}$ & H-1>L: 0.68 & 347 & 0.069 & & \\
\hline (3) LE: $n-\pi^{*}$ & H-2->L: 0.68 & 344 & 0.0002 & & \\
\hline (4) CT: $\pi-\pi^{*}$ & H-3->L: 0.66 & 301 & 0.256 & 309 & 3.75 \\
\hline (5) LE: $n-\pi^{*}$ & H-4>L: 0.69 & 294 & 0.0002 & & \\
\hline (6) CT: $\pi-\pi^{*}$ & H-5>L: 0.55 & 241 & 0.028 & 263 & 3.97 \\
\hline
\end{tabular}

(a) PCM-TD-DFT(B3LYP)/6-31+G(d,p)//PCM-DFT(B3LYP)/6-311G(d,p).

TABLE 4: Key geometrical parameters $(r, \theta)$, HOMO, LUMO energy levels of $(\mathbf{3 a}-\mathbf{d})$ and $(\mathbf{5 a}-\mathbf{g})$.

\begin{tabular}{ccccc}
\hline & $r$ & $\theta$ & HOMO (a.u.) & LUMO (a.u.) \\
\hline 3a & 1.405 & 0.5 & -0.232 & -0.119 \\
3b & 1.419 & 3.0 & -0.226 & -0.111 \\
3c & 1.420 & 32.3 & -0.232 & -0.120 \\
3d & 1.433 & 38.9 & -0.227 & -0.112 \\
$\mathbf{5 a}$ & 1.420 & 23.4 & -0.223 & -0.115 \\
$\mathbf{5 b}$ & 1.422 & 37.4 & -0.221 & -0.114 \\
$\mathbf{5 c}$ & 1.428 & 42.6 & -0.219 & -0.117 \\
$\mathbf{5 d}$ & 1.432 & 33.6 & -0.217 & -0.105 \\
$\mathbf{5 e}$ & 1.435 & 39.0 & -0.217 & -0.106 \\
$\mathbf{5 f}$ & 1.430 & 40.4 & -0.215 & -0.107 \\
$\mathbf{5 g}$ & 1.439 & 46.6 & -0.212 & -0.107 \\
\hline
\end{tabular}

Using PCM-DFT(B3LYP)/6-311G(d,p).

$\lambda_{\max }$ inversely, giving $1 \mathrm{~nm}$ red shift relative to that of $6-31 G(\mathrm{~d}, \mathrm{p})$. The blue-shift (polarization, valence-splitting) and red-shift effect (diffuse) were also observed in the case of thioindigo dyes [11]. Moving on to the basis set effect used in TDDFT, the basis set improvement gave $12 \mathrm{~nm}$ red shift going from $6-31 \mathrm{G}$ to $6-311++\mathrm{G}(2 \mathrm{~d}, 2 \mathrm{p})$ for the most expensive $6-311++\mathrm{G}(2 \mathrm{~d}, 2 \mathrm{p})$-optimized geometry. In details, $6-311 \mathrm{G}(2 \mathrm{~d}, 2 \mathrm{p})$ gave no red shift from 6-31G, an indication of the minor influence of polarization and double/triple zeta splitting. On the other hand, $6-31+G(d)$ gave considerable red shift of $10 \mathrm{~nm}$ in comparison with 6-31G, which means the critical role of diffuse function. These trends are also found in the case of diazonium ion with minor contribution of polarization and diffuse enhancement [11], anthraquinone derivatives with polarization and valence-splitting [12], but are sharp contrast to the case of thioindigo dyes where the three types of basis set enhancements (polarization, valence-splitting, and diffuse function) monotonically gave substantial redshift effects [11]. The $\lambda_{\max }$ gap between the moderate-scale PCM-TD-DFT(B3LYP)/6-31+G(d,p)//PCM-DFT(B3LYP)/ $6-311 \mathrm{G}(\mathrm{d}, \mathrm{p})$ and the most exhaustive calculation PCMTD-DFT(B3LYP)/6-311++G(2d,2p)//PCM-DFT(B3LYP)/6$311++G(2 d, 2 p)$ is less than $1 \mathrm{~nm}$. We therefore can safely use PCM-TD-DFT(B3LYP)/6-31+G(d,p)//PCMDFT(B3LYP)/6-311G(2d,2p) as a well-balanced scheme both accuracy and computational burden. The influence of XC-functionals for TDDFT calculations was subsequently examined consistently using the optimized geometry obtained by DFT(B3LYP)/6-311G(d,p). The mixing weight of exact (Hartree-Fock) exchange in XC hybrid functionals critically affects the calculated $\lambda_{\max }$ [11]; O3LYP with $11.67 \%$, B3LYP with $20 \%$, PBE0 with $25 \%$, respectively. The calculated $\lambda_{\max }$ is shifted hypsochromically as the mixing percentage rises, $457 \mathrm{~nm}$ (O3LYP), $448 \mathrm{~nm}$ (B3LYP), and $439 \mathrm{~nm}$ (PBE0). Other functionals, GGA (BLYP), meta-GGA (VSXC), and asymptotically corrected functional (HCTH/407) predicted red-shifted $\lambda_{\max }, 485,463$, and $478 \mathrm{~nm}$, respectively, in comparison to the experimental $\lambda_{\max } 459 \mathrm{~nm}$. Slight influence of the correlation term to $\lambda_{\max }$ was indicated with the gap between B3LYP and B3PW91 being only $2 \mathrm{~nm}$. These XC-functional influences are in a qualitative agreement to our previous TDDFT results [13]. 
TABLe 5: Calculated $\lambda_{\max }(\mathrm{nm})$ dependence on XC functionals for (3a-3d) and (5a-5g).

\begin{tabular}{lccccccccccc}
\hline & B3PW91 & B3LYP & O3LYP & BLYP & PBE0 & VSXC & MPW1PW91 & HCTH & Expl. & ${ }^{1}$ Relative Err.(\%) & ${ }^{2}$ RMS(\%) \\
\hline 3a & 446 & 448 & 457 & 485 & 439 & 463 & 439 & 478 & 459 & 0.46 \\
3b & 444 & 447 & 456 & 487 & 436 & 462 & 436 & 481 & 456 & 0.03 \\
3c & 464 & 466 & 476 & 507 & 455 & 487 & 455 & 500 & 437 & 8.98 \\
3d & 467 & 470 & 484 & 525 & 456 & 503 & 456 & 517 & 435 & 11.4 \\
5a & 495 & 499 & 516 & 568 & 481 & 542 & 481 & 558 & 470 & 10.1 \\
5b & 515 & 519 & 540 & 598 & 499 & 571 & 499 & 588 & 497 & 8.88 \\
5c & 561 & 567 & 592 & 668 & 541 & 640 & 542 & 653 & 504 & 18.2 \\
5d & 491 & 495 & 518 & 578 & 475 & 548 & 475 & 567 & 444 & 16.8 \\
5e & 500 & 505 & 527 & 591 & 483 & 564 & 483 & 579 & 456 & 16.0 \\
5f & 520 & 524 & 546 & 605 & 503 & 577 & 504 & 594 & 485 & 10.1 \\
5g & 554 & 561 & 587 & 665 & 533 & 635 & 533 & 649 & 493 & 9.27 \\
\hline
\end{tabular}

All $\lambda_{\max }$ calculated by PCM-TDDFT/6-31+G(d,p)//PCM-DFT(B3LYP)/6-311G(d,p).

${ }^{1}$ Percentage of relative errors averaged among $8 \mathrm{XC}$ functionals.

${ }^{2}$ Relative standard deviation between computed $\lambda_{\max }$ and experimental $\lambda_{\max }$.

The optimized TDDFT scheme above-mentioned characterized the low-lying six singlet excited states for $\mathbf{3} \mathbf{a}$, as in Table 3. The first, fourth, and sixth transitions originate from the $\pi \pi^{*}$ transitions on the whole molecular plain. The first intense peak, dominantly describable with the HOMO-LUMO excitation, has large oscillator strength $(f)$ of 0.34 . The second local excitation (LE) originates from HOMO-1 (mainly distributed on pyrrole ring) to LUMO with moderate $f$ of 0.069 . The third peak is of $n-\pi^{*}$ character with negligibly small $f$ of 0.0002 . The fourth $\pi-$ $\pi^{*}$ transition derives from HOMO-3 (mainly distributed on maleimide ring) to LUMO with moderate $f$ of 0.256 . The fifth peak is of $n-\pi^{*}$ character with negligibly small $f$ of 0.0002 . The sixth $n-\pi^{*}$ transition has moderate $f$ of 0.0281 . The first computed $\pi-\pi^{*}$ transition at 448 (PCM-TD-DFT(B3LYP)/6-31G $(\mathrm{d}, \mathrm{p})$ ) $\mathrm{nm}$ is ascribed to the first intense visible band at $459 \mathrm{~nm}$, the fourth transition to the second band at $309 \mathrm{~nm}$, and the sixth transition to the third UV band at $263 \mathrm{~nm}$. The second, third, and fifth transitions with small $f$ are thought to be hidden in the spectra.

4.2. Other Maleimide Derivatives $\mathbf{3 b}-\mathbf{3} \mathbf{d}$ and $\mathbf{5 a} \mathbf{a}-\mathbf{g}$. Following the assessment in the previous subsection, we consistently applied PCM-TD-DFT/6-31+G(d)//PCM-DFT(B3LYP)/6$311 \mathrm{G}(\mathrm{d}, \mathrm{p})$ to the remaining molecules $\mathbf{3 b}-\mathbf{3 d}$ and $\mathbf{5 a}-\mathbf{g}$. Table 4 shows the interring bond lengths and the tortional angles along with the HOMO and LUMO levels. The TDDFT-predicted first peak positions are listed in Table 5 along with the experimental ones and the statistical parameters.

$\mathbf{3} \mathbf{a}$ and $\mathbf{3} \mathbf{b}$ with little intramolecular steric hindrance hold nearly planar geometry while $\mathbf{3} \mathbf{c}$ and $\mathbf{3 d}$ have twisted geometries because of the steric repulsion between methylpyrrole and maleimide ring. The interring bond lengths of $3 \mathbf{a}$ and $\mathbf{3 b}$ are therefore appreciably shorter than those of $\mathbf{3 c}$ and $\mathbf{3 d}$ because the $\pi$-conjugation in the molecular plain is fully restored. Concerning the theoretical $\lambda_{\max }$ dependence on XC hybrid functionals, O3LYP functional (with low mixing ratio of exchange term) showed excellent agreements for planar molecules $\mathbf{3} \mathbf{a}$ and $\mathbf{3} \mathbf{b}$ but appreciably longer $\lambda_{\max }$ for distorted compounds $\mathbf{3 c}$ and $\mathbf{3 d}$. PBE0 and MPW91PW91 (with high mixing ratio of exchange term), inversely, gave worse agreement in case of $\mathbf{3 a}$ and $\mathbf{3 b}$ while a better agreement for $3 \mathrm{c}$ and $\mathbf{3 d}$. The hybrid functionals B3PW91, B3LYP, and O3LYP gave underevaluated peaks in this order, with the peaks being blue-shifted proportional to the mixing ratio of an exact exchange term. Using the other functionals, the amplitude of $\lambda_{\max }$ displacement is severely large; BLYP-, VSXC-, and HCTH-predicated peaks showed large deviations particularly for $\mathbf{3 c}$ and $\mathbf{3 d}$. In our previous TDDFT study [13], we found some specific features and limitations of theoretical $\lambda_{\max }$ for the newly prepared maleimide derivatives, where the molecules with large twist angle showed better $\lambda_{\max }$ agreement owing to efficient charge separation between the two moieties while PBE0 and MPW91PW91 gave better $\lambda_{\max }$ agreements than other functionals and the agreements worsen for planar compounds. All types of XC-fuctionals employed failed to reproduce hypsochromic shift of $\mathbf{3} \mathbf{c}$ and $\mathbf{3 d}$ in comparison with $\mathbf{3 a}$ and $\mathbf{3} \mathbf{b}$. This is because theoretical $\lambda_{\max }$ of nearplanar $\mathbf{3} \mathbf{a}$ and $\mathbf{3 b}$ are underevaluated while those of twisted $\mathbf{3 c}$ and $\mathbf{3 d}$ overvaluated, leading to this fictitious switching.

$\mathbf{5 a}-\mathbf{5 g}$ apparently hold distorted geometry with the two $\pi$-moieties being well separated. The qualitative agreements (within $40 \mathrm{~nm}$ deviations between theory and experiment) were obtained using PBE0 and MPW1PW91. The theoretical peaks however were overvaluated with all the XCfunctionals, particularly for $\mathbf{5 g}$ using VSXC and HCTH functionals by more than $100 \mathrm{~nm}$ deviations. The theoretical $\lambda_{\max }$ displayed systematic red-shifted tendencies in the order B3PW91 $<$ B3LYP $<$ O3LYP for hybrid functionals, which is proportional to the mixing ratio of an exact exchange term, as in case of $\mathbf{3 a} \mathbf{a}-\mathbf{3 d}$.

The relative errors and the relative standard deviations in Table 5 indicate that a qualitative agreement is obtained 
between theoretical $\lambda_{\max }$ and experiment for $\mathbf{3 a}, \mathbf{3} \mathbf{b}$, and $3 \mathbf{c}$, while other molecules show a worse agreement. This is due to the considerable red-shift deviations when using VSXC and HCTH functionals which are not well optimized for twisted $\pi$-conjugated systems.

\section{Conclusion}

New maleimide derivatives bearing pyrrole and indole ring were synthesized and assessed for their UV/vis spectra experimentally and computationally. Experimental UV/vis $\lambda_{\max }$ were observed in 435-504 nm. TDDFT analysis (PCM-TDDFT / 6-31 + G(d,p)//PCM-DFT(B3LYP) / 6-311G(d,p)) for the first intense peak of the compounds was done to obtain semiquantitative agreements between experimental and theoretical $\lambda_{\max }$ for the compounds.

\section{References}

[1] R. Huisgen, 1,3-Dipolar Cycloaddition Chemistry, John Wiley \& Sons, New York, NY, USA, 1984.

[2] Y. Tominaga, N. Yoshioka, and S. Kataoka, "Synthesis of amino-pyrimidopyrtoazines as chemiluminescent compounds by reaction of functionalized maleimide with various amine derivatives," Heterocycles, vol. 43, no. 8, pp. 1597-1600, 1996.

[3] Y. Shigemitsu, M. Sugimoto, S. Itonaga, K. Komiya, and Y. Tominaga, "Synthesis and electronic spectra of novel merocyanine dyes bearing a maleimide ring incorporated into the methine chains," Dyes and Pigments, vol. 56, no. 2, pp. 167$179,2003$.

[4] Y. Shigemitsu, K. Komiya, N. Mizuyama, and Y. Tominaga, "Reaction of functionalized maleimides with versatile nucleophiles. Synthesis, electronic spectra and molecular orbital study," Dyes and Pigments, vol. 72, no. 3, pp. 271-284, 2007.

[5] M. E. Casida, Recent Advances in Density Fucntional Method, World Scientific, Singapore, 1995.

[6] C. Adamo, G. E. Scuseria, and V. Barone, "Accurate excitation energies from time-dependent density functional theory: assessing the PBE0 model," The Journal of Chemical Physics, vol. 111, no. 7, pp. 2889-2899, 1999.

[7] S. Hirata, M. Head-Gordon, and R. J. Bartlett, "Configuration interaction singles, time-dependent Hartree-Fock, and timedependent density functional theory for the electronic excited states of extended systems," The Journal of Chemical Physics, vol. 111, no. 24, pp. 10774-10786, 1999.

[8] Gaussian 03, Revision C.02, Gaussian, Inc., Wallingford CT, 2004.

[9] G. Zhurko, ChemCraft ver.1.5, 2005.

[10] D. Jacquemin, J. Preat, and E. A. Perpète, "A TD-DFT study of the absorption spectra of fast dye salts," Chemical Physics Letters, vol. 410, no. 4-6, pp. 254-259, 2005.

[11] D. Jacquemin, J. Preat, V. Wathelet, and E. A. Perpète, "Theoretical investigation of the absorption spectrum of thioindigo dyes," Journal of Molecular Structure: THEOCHEM, vol. 731, no. 1-3, pp. 67-72, 2005.

[12] D. Jacquemin, J. Preat, M. Charlot, V. Wathelet, J.-M. André, and E. A. Perpète, "Theoretical investigation of substituted anthraquinone dyes," The Journal of Chemical Physics, vol. 121, no. 4, pp. 1736-1743, 2004.
[13] Y. Shigemitsu, K. Komiya, N. Mizuyama, and Y. Tominaga, "TD-DFT investigation on the electronic spectra of novel $\mathrm{N}$ methylmaleimides linked with indolizine ring system," Journal of Molecular Structure: THEOCHEM, vol. 855, no. 1-3, pp. 92$101,2008$. 


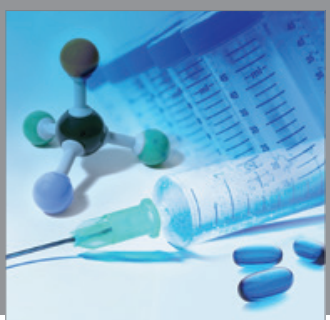

International Journal of

Medicinal Chemistry

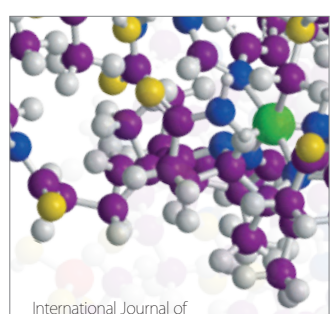

Carbohydrate Chemistry

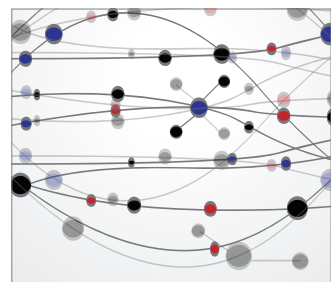

The Scientific World Journal
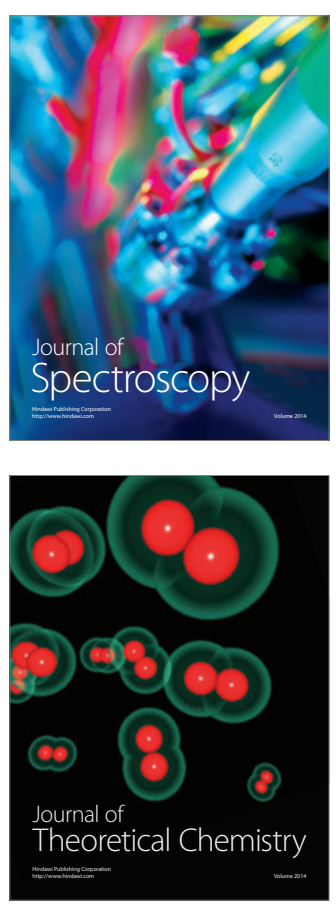
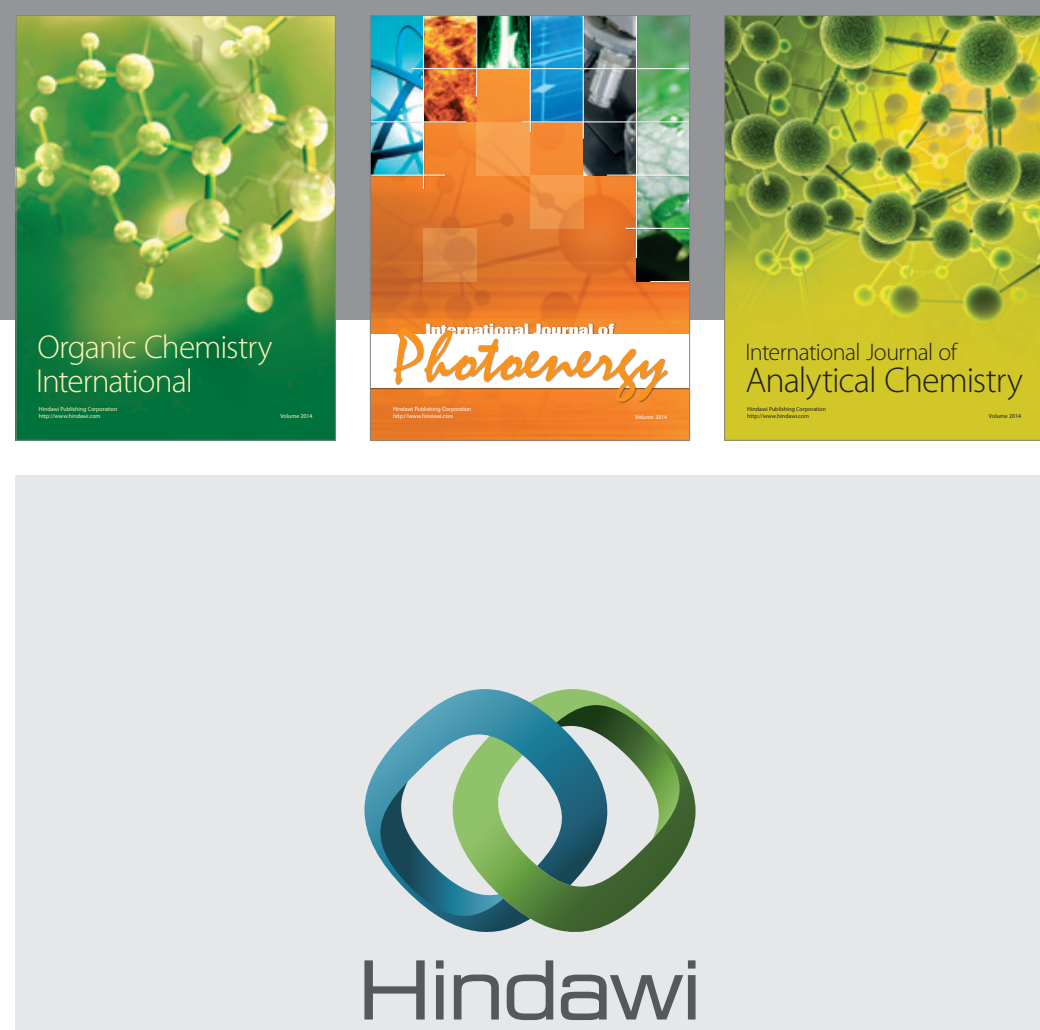

Submit your manuscripts at

http://www.hindawi.com
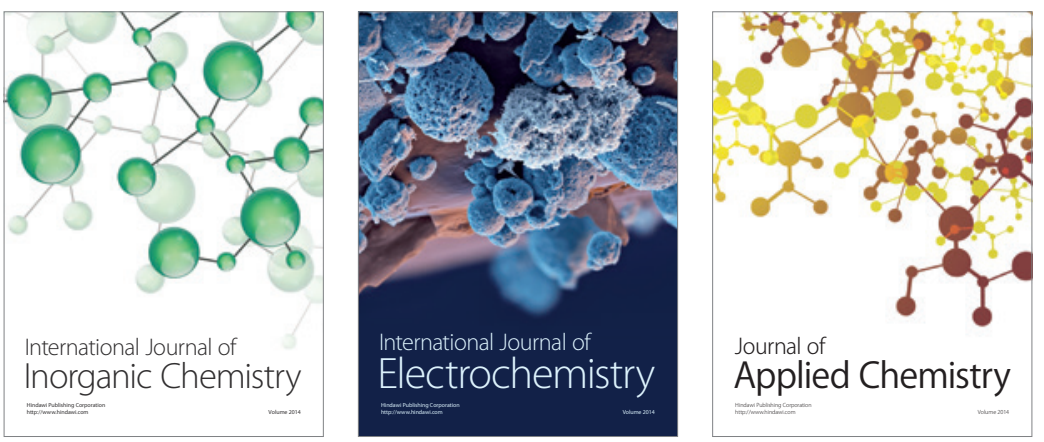

Journal of

Applied Chemistry
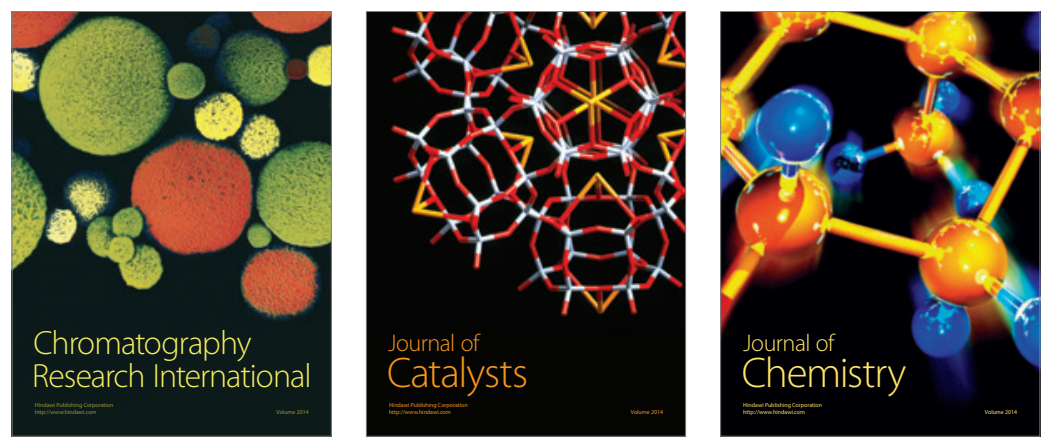
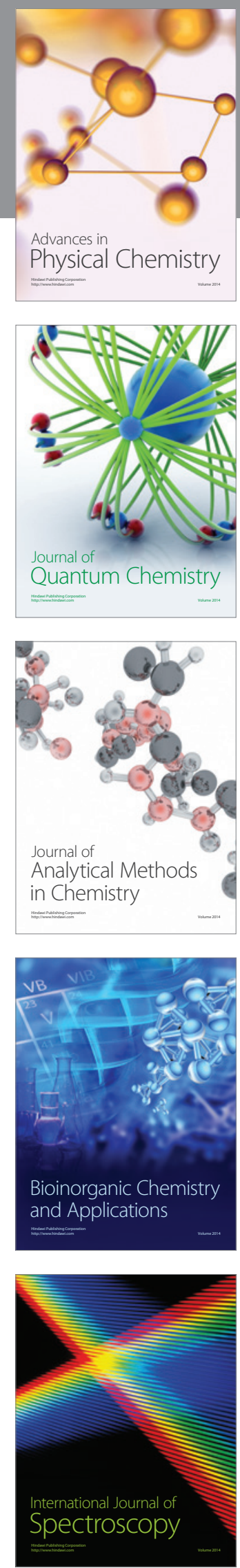